\title{
Joint Action of Disease Control Measures: A Case Study of Alternaria Leaf Blight of Carrot
}

\author{
E. Ben-Noon, D. Shtienberg, E. Shlevin, and A. Dinoor
}

First and second authors: Department of Plant Pathology, ARO, the Volcani Center, Bet Dagan 50250, Israel; third author: Kibbutz Sa'ad, NP Negev, 85140, Israel; and first and fourth authors: Department of Plant Pathology and Microbiology, Faculty of Agricultural Food and Environmental Quality Sciences, the Hebrew University of Jerusalem, Rehovot 70600, Israel. Accepted for publication 31 May 2003.

\begin{abstract}
Ben-Noon, E., Shtienberg, D., Shlevin, E., and Dinoor, A. 2003. Joint action of disease control measures: A case study of Alternaria leaf blight of carrot. Phytopathology 93:1320-1328.

The efficacy of chemical (i.e., foliar fungicide sprays), genetic (i.e., moderately resistant cultivars), and cultural (i.e., drip-irrigation system) control measures was quantified individually and in combination in the management of Alternaria dauci, the causal agent of Alternaria leaf blight of carrot. Whereas host resistance and drip irrigation affected both the time of disease onset and the rate of disease progression, chemical control affected only the latter. In all cases, a single control measure did not provide an acceptable level of disease suppression. Control efficacy values (based on the relative area under the disease progress curve) for chemical, genetic, and cultural control were $58 \pm 11,39 \pm 20$, and $60 \pm$ $22 \%$, respectively (values are means \pm standard error). By contrast, implementing two control measures concurrently always improved disease

measures and $82 \pm 23 \%$ for the integration of chemical and cultural measures. Moreover, yields in plots protected by two control measures simultaneously were higher by 10.1 to $28.6 \mathrm{t} / \mathrm{ha}$ than those in the respective plots protected by single measures. The joint effect of chemical control and host resistance was additive, whereas that of chemical control and drip irrigation was synergistic in most cases. A literature review was performed to determine if these findings represent a general relationship between chemical and genetic, and chemical and cultural measures. Based on 19 reviewed cases, it was concluded that additive effects are the rule and synergistic or antagonistic effects are the exception. Synergistic effects of two control measures were observed when one control measure improved the efficacy of the other directly or when one control measure induced host resistance or predisposed the pathogen to increased susceptibility. These results may enable a more effective selection of candidate control measures for integration in the future.
\end{abstract} suppression significantly compared with the individual measures. Control efficacy values were $91 \pm 8 \%$ for the integration of chemical and genetic
Additional keywords: Daucus carota, integrated pest management.
Adequate management of plant diseases is a prerequisite for stable and profitable production of food and fibers. Many and varied control measures are available for this purpose, including chemical, cultural, biological, and genetic ones. In most cases, growers rely on a single measure for disease suppression. However, joint application of two or more control measures may be advantageous, for several reasons. First, it may enable acceptable disease suppression in cases where sole measures are not effective enough. For example, applying fungicides to susceptible chickpea cultivars did not result in adequate suppression of Didymella rabiei, the causal agent of Ascochyta blight, but integration of chemical control and host resistance significantly improved disease control and enabled the potential yield to be achieved (33). The simultaneous implementation of more than one control measure may enable the use of potentially environmentally harmful measures such as chemical fungicides or fumigants to be minimized, either by reducing their rates or by decreasing the number of applications. For example, the use of moderately resistant cultivars enabled reduction of both fungicide dosages and the total quantity used in a growing season in the management of Phytophthora infestans, the causal agent of late blight in potato (10-12); integration of a biocontrol agent, Trichoderma harzianum T39, with fungicides enabled $\mathrm{a} \approx 70 \%$ reduction in the number of

Corresponding author: D. Shtienberg; E-mail address: danish@volcani.agri.gov.il

Publication no. P-2003-0818-03R

This article is in the public domain and not copyrightable. It may be freely reprinted with customary crediting of the source. The American Phytopathological Society, 2003. chemical sprays, while still achieving adequate suppression of Botrytis cinerea in tomato and cucumber greenhouses (31); integration of host resistance, age-related resistance, and chemical control against potato early blight (caused by Alternaria solani) enabled the number of fungicide applications to be reduced without impairing the level of disease suppression (30); and combination with solarization enabled methyl bromide dosages to be reduced by up to $50 \%$ while maintaining adequate suppression of soilborne pathogens (19). Integration of control measures also may increase the effective life span of a specific control measure; for example, by reducing the probability of the development of pathogen populations resistant to fungicides, or of the development of pathogen populations virulent on resistant cultivars. Finally, integration of control measures may reduce the inconsistency and lack of repeatability experienced with the sole application of some control measures. This was reported, for example, in the suppression of $B$. cinerea by $T$. harzianum T39 when the biocontrol agent was integrated with fungicides (31) and in the suppression of $B$. cinerea by combining two biocontrol agents, a yeast (Pichia guilermondii) and a bacterium (Bacillus mycoides) (16).

When two control measures are applied together, the resultant effect on the pathogen may be antagonistic, additive, or synergistic (20,21). Antagonistic effects result in the efficacy of the integrated measures being lower than the sum of those of the individual components; additive effects are those in which the efficacy of the integrated measures is equal to the sum of the separate ones; and synergistic effects result in the efficacy of the integration being larger than the sum of the separate ones $(20,21)$. The quantitative effects of integrating various control measures on plant disease suppression have not been studied previously. On the 
other hand, the joint action of fungicides, when applied in mixtures, was thoroughly investigated. Synergy is a frequent phenomenon in fungicide mixtures. Its magnitude depends on the ratio of the components in the mixture and their modes and mechanisms of action, because fungicide with different modes of action may affect the pathogen at different biochemical sites and developmental stages. Differences in systemicity and uptake into the pathogen and plant as well as different physiochemical properties and rates of metabolization also are important $(5,13,29)$. If it was possible to predict, in a similar manner, the nature of the joint action of other control measures, the development of integrated pest management (IPM) strategies could be improved. Not only would such a capability assist in choosing the more promising candidate measures for integration, but it also might provide insights into the interrelationships between the different control measures used and their effects on the pathogen. In the present study, the Alternaria leaf blight-carrot pathosystem was used to determine the efficacy of chemical, genetic, and cultural control measures when applied alone or when integrated with each other.

Alternaria leaf blight, caused by Alternaria dauci (Kühn) Groves \& Skolko., is a major foliar disease of carrot (Daucus carota L. var. sativa DC.) in Israel $(1,22)$ and other countries $(35,36)$. The disease damages carrot plants by rapidly blighting or killing the leaves. Such damage usually results in poor growth and leads to harvesting problems, because leaves weakened by blight often break off when gripped by a mechanical harvester. Severe epidemics of Alternaria leaf blight may reduce carrot yields by 40 to $60 \%(1,36)$. Chemical control is the primary means used by carrot growers in Israel and elsewhere for disease management, and a recent study in Israel aimed to optimize chemical suppression of the disease in order to reduce fungicide use (1). Further improvement in disease management might be achieved by integration of chemical control with other control measures.

Data on integration of various control measures in the management of $A$. dauci are scarce. More information is available for other Alternaria diseases, such as A. solani in potato and tomato and A. macrospora in cotton. Integration of host resistance, agerelated resistance, and increased nitrogen fertilization with chemical control led to improved disease suppression and reduced fungicide use in these pathosystems. Carrot cultivars immune to A. dauci are not available, but cultivars differ in their susceptibility to the pathogen (14). The epidemiological basis for this resistance is not known, and possible contribution of host resistance to the management of $A$. dauci in carrot has not yet been explored. In potato, receptivity was longer, the incubation period was shorter, and the rate of lesion expansion on leaves was greater in cultivars susceptible to $A$. solani than in those moderately resistant to it. On the other hand, differences in spore production by $A$. solani on susceptible and on moderately resistant cultivars were insignificant $(17,25,26)$. In potato and cotton, it was demonstrated that moderately resistant cultivars can be sprayed with fungicides less frequently than susceptible cultivars and still exhibit adequate disease suppression $(30,34)$.

All carrot fields in Israel are irrigated once or twice a week; the frequency depends on the growing season. Most fields are irrigated via overhead sprinklers, and this is done at night when the foliage is already wet with dew to avoid prolonging the wetness period. However, it still is possible that overhead irrigation directly or indirectly affects the intensity of Alternaria leaf blight epidemics. It could be that daytime wetness is prolonged even when irrigation is performed at night and terminates just before sunrise. Moreover, it is likely that water-drop splashing assists the dissemination of Alternaria conidia at night, when conditions are highly favorable for their germination (28). Sprinkler irrigation also may impair the efficacy of the chemical sprays applied for the management of Alternaria leaf blight by washing the fungicide deposits off the foliage $(23,24)$. Accordingly, use of a drip irrigation system rather than an overhead sprinkler system might avoid altering the microclimatic conditions in favor of the pathogen and also might improve chemical suppression of Alternaria leaf blight.

In the present study, the joint action of chemical (i.e., foliar fungicide sprays) and genetic (i.e., moderately resistant cultivars) disease control measures was quantified and compared with that of integrated chemical and cultural (i.e., drip irrigation system) measures in the management of Alternaria leaf blight of carrot. The findings regarding the nature of the resultant joint action then were compared with published reports on other pathosystems in an attempt to identify common features and generalities.

\section{MATERIALS AND METHODS}

Cultural practices and experimental design. Four field experiments were conducted from 1996 to 1998 to determine the benefits gained by integrating control measures in the suppression of Alternaria leaf blight. The experiments were conducted in the northern Negev region in Israel in experimental plots and in commercial carrot fields. Carrot seed were sown in rows at density of $80 \mathrm{seed} / \mathrm{m}$ of row. There were three rows per bed and the distance between beds was $1.8 \mathrm{~m}$. General crop maintenance was as recommended to commercial carrot growers in that region. Unless stated otherwise, irrigation was applied via overhead sprinklers at night, twice a week. In three of the experiments, fungicides (in 250 to 300 liters of water/ha) were applied with a motorized backpack sprayer through Cone-Jet X8 nozzles (Spraying Systems, Wheaton, IL) at a pressure of $275 \mathrm{kPa}$. In the fourth experiment, fungicides (in 300 liters of water/ha) were applied by means of a tractor-mounted boom sprayer equipped with Cone Jet X6 nozzles at a pressure of $350 \mathrm{kPa}$. In accordance with the fungicides' labels, none of the sprays contained any additional spreader, sticker, or adjuvant. Carrot plants in the experimental plots were harvested just before those in adjacent commercial fields. An area of $1.2 \mathrm{~m}^{2}$ in the center of each experimental plot was harvested manually. Roots were removed, washed, and weighed and the yield per hectare was calculated.

Joint action of chemical control and host resistance. The interacting effects of chemical control and host resistance were determined in two experiments; the first was planted on 9 July 1996 and the second on 9 July 1997. The experiments were laid out in a split-plot design with two factors. In the 1996 experiment, the first factor-host resistance (in the main plots)—was applied at five levels: the carrot cvs. Bolero, Predor, Presto, Senior, and Valor. The second factor-chemical control (in the subplots) was applied at two levels: unsprayed and fungicide-sprayed plots. Each treatment combination was replicated five times. The main experimental plots were one bed wide and $16 \mathrm{~m}$ long; the subplots were one bed wide and $8 \mathrm{~m}$ long. The systemic fungicide tebuconazole (Folicur; Bayer Crop Science, Mannheim, Germany) was applied at a rate of $0.19 \mathrm{~kg}$ a.i./ha starting 27 days after planting and continuing at 7-day intervals until the end of the season; 10 sprays were applied in total. Carrot yield was collected 93 days after planting. Because of variations in the stand of some of the experimental plots of cv. Senior, yield was not determined for that cultivar.

In the 1997 experiment, the treatments were the same as above, except that the factor in the main plots was chemical control and that in the subplots was host resistance. Each treatment combination was replicated four times. The main experimental plots were five beds wide and $16 \mathrm{~m}$ long; the subplots were one bed wide and $16 \mathrm{~m}$ long. The fungicides tebuconazole (at $0.19 \mathrm{~kg}$ a.i./ha) and iprodione (Rovral, at $0.5 \mathrm{~kg}$ a.i./ha; Bayer Crop Science) were applied alternately. Fungicides in this experiment were applied by a tractor-mounted boom sprayer starting 20 days after planting and continuing until the end of the season; a total of 25 sprays were applied. Carrot yield was determined 110 days after planting.

Joint action of chemical control and drip irrigation. The interacting effects of chemical control and the type of the irriga- 
tion system were determined in two experiments: the first was planted on 18 July 1997 and the second on 8 July 1998. The cultivar used in these experiments was Presto. The experiments were laid out in a split-plot design with two factors. In the 1997 experiment, the first factor-type of irrigation system (in the main plots)—was applied at two levels: sprinkler-irrigated plots and drip-irrigated plots. The second factor-chemical control (in the subplots)—was applied at three levels: (i) unsprayed, (ii) tebuconazole (at $0.19 \mathrm{~kg}$ a.i./ha), and (iii) the protectant fungicide mancozeb (Manzidan, at $2 \mathrm{~kg}$ a.i./ha; Dow AS, Paris, France). Each treatment combination was replicated four times. The main experimental plots were six beds wide and $8 \mathrm{~m}$ long; the subplots were one bed wide and $8 \mathrm{~m}$ long. The main plots were separated from each other by a 6-m-wide fallow area. Irrigation was applied twice a week at night, using the same quantity of water in both irrigation treatments. Fungicides were applied starting 33 days after planting and continuing at 7-day intervals until the end of the season; a total of nine sprays were applied. The yield of the sprinkler-irrigated plots was harvested 87 days after planting and that of the drip-irrigated plots 107 days after planting.

The layout of the 1998 experiment was similar to that of the 1997 experiment. Differences were as follows: the main plots were three beds wide and $8 \mathrm{~m}$ long and the subplots were one bed wide and $8 \mathrm{~m}$ long. Spraying was initiated 40 days after planting and a total of six sprays were applied. Carrot yield was harvested 91 days after planting.

Disease assessment and data analyses. Experimental plots were not inoculated artificially with $A$. dauci because inoculum was naturally present at the test sites in the form of airborne spores from adjacent fields. The crop was inspected every 3 to 6 days starting 2 weeks after emergence. After the first disease symptoms on true leaves were observed, disease severity (expressed as the percentage of the aerial plant tissue affected, including leaf blade and petiole lesions) was visually assessed according to the HorsfallBarratt grading system (18). Assessments were performed every
6 to 10 days until harvest. Two individuals (the same ones throughout each experiment) made assessments on a whole-plot basis and the scores were averaged between assessors and replicated plots. For data analyses, the Horsfall-Barratt ratings were converted to disease percentage values. Logit-transformed severity values $(\operatorname{logit}=\ln [y /(100-y)]$; where $y=$ percent disease severity) were used to calculate by regression the apparent infection rate $(r)$. The area under the disease progress curve (AUDPC) was calculated on the basis of the season-long disease assessments; the period used for calculating AUDPC values extended from the date of the first appearance of disease to the last disease assessment. To compare AUDPC values from different experiments, the relative area under the disease progress curve (RAUDPC) was calculated by dividing AUDPC by the duration of the epidemic. RAUDPC units are percentages. The disease severity or RAUDPC values recorded in treated plots $\left(D_{t}\right)$ and in reference plots $\left(D_{r}\right)$ were used to calculate control efficacy $\left(\mathrm{CE}_{t}\right.$, as a percentage) achieved by each treatment: $\mathrm{CE}_{t}=\left(1-D_{t} / D_{r}\right) \times 100$.

In quantifying the joint action of chemical control and host resistance, the disease intensity (expressed as RAUDPC) in unsprayed plots of the most susceptible cultivar, Presto, was used as the reference treatment. The contribution of chemical control was estimated by comparing the disease intensity values recorded in fungicide-treated plots of Presto with the reference treatment; that of host resistance was estimated by comparing the disease intensity values recorded in unsprayed plots of the most resistant cultivars used (Senior and Bolero) with the reference treatment. Disease intensity records in fungicide-treated plots of Senior and Bolero were used to estimate the observed joint contribution of chemical control and host resistance. In quantifying the joint action of chemical control and drip irrigation, the disease intensity (expressed as RAUDPC) in sprinkler-irrigated, unsprayed plots, was used as the reference treatment. The contribution of chemical control was estimated by comparing the disease intensity values recorded in sprinkler-irrigated, fungicide-treated plots with the

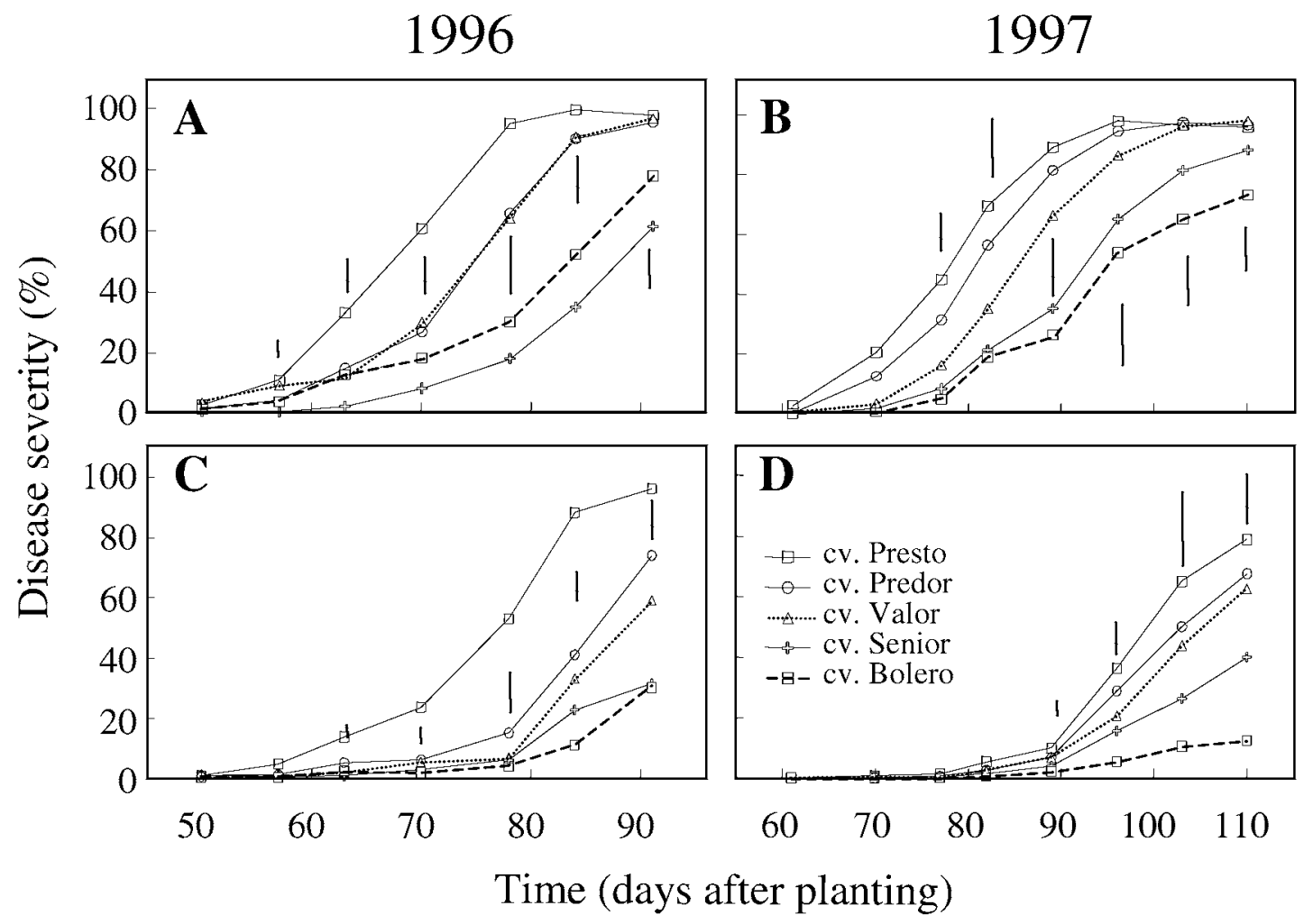

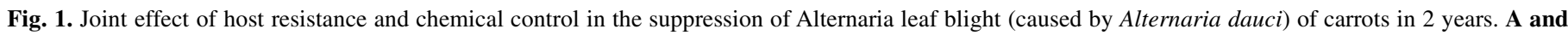

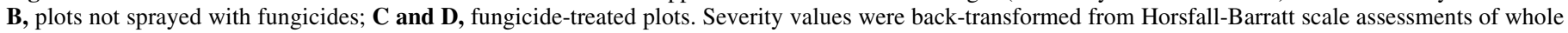
plots. Vertical lines indicate the least significant difference $(P=0.05)$ for each disease assessment date. 
reference treatment; that of drip irrigation was estimated by comparing the disease intensity values recorded in drip-irrigated, unsprayed plots with the reference treatment. Disease intensity records in drip-irrigated, fungicide-treated plots were used to estimate the observed joint contribution of chemical control and drip irrigation.

The joint action of the control measures used was estimated by means of the Abbott formula (20,21). The expected disease control efficacy and the joint suppression action against $A$. dauci were calculated as follows: $\mathrm{CE}_{\exp }=a+b-a \times b / 100$ and $\mathrm{SF}=$ $\mathrm{CE}_{\text {obs }} / \mathrm{CE}_{\text {exp }}$, where $a=$ control efficacy of one measure when applied alone, $b=$ control efficacy of the other measure when applied alone, $\mathrm{CE}_{\text {exp }}=$ expected control efficacy of the integration if the two measures act additively, $\mathrm{CE}_{\mathrm{obs}}=$ observed control efficacy of the integration, and SF = the synergy factor achieved by the integration. When SF $=1$, the interaction between the control measures is additive; when $\mathrm{SF}<1$, the interaction is antagonistic, and when SF $>1$, the interaction is synergistic $(20,21)$. Statistical analysis was done based on the data from the replicated plots. Data were subjected to Student's $t$ test, analysis of variance (ANOVA), or regression analyses, as appropriate. When the $F$ statistic of ANOVA was significant at $P \leq 0.05$, the least significant difference (LSD) was calculated according to Fisher's protected LSD test. Statistical analyses of the data were performed using the JMP-in software (version 3 for Windows; SAS Institute, Cary, NC).

\section{RESULTS}

Joint action of chemical control and host resistance. The first disease symptoms were observed in unsprayed plots of cv. Presto,
45 and 53 days after planting in 1996 and 1997, respectively. Disease severity in these plots had reached $\approx 80 \%$ (Fig. $1 \mathrm{~A}$ and $\mathrm{B}$ ) $\approx 1$ month later. There were significant differences among the responses of the different carrot cultivars to A. dauci. Based on final disease severity, $r$, and RAUDPC, the responses of the cultivars to $A$. dauci were ranked as follows: Presto (most susceptible), Predor, Valor, Senior, and Bolero (most resistant). In plots of the most susceptible cv. Presto, the disease had started to intensify 2 weeks earlier and $r$ was significantly higher than in those of the most resistant cvs. Senior and Bolero (Fig. 1A and B; Table 1). The contributions of host resistance alone to the reduction of disease intensity in 1996 and 1997 were 12.5 and $28.8 \%$, respectively, for the least resistant cultivar (Predor) and ranged from 53.1 to $72.8 \%$ for the most resistant cvs. Senior and Bolero (Table 2). Nevertheless, the disease continued to develop and, by the end of the season, it reached severity levels of 60 to $65 \%$ even in the most resistant cultivars (Fig. 1A and B).

Application of fungicide was highly effective in suppressing Alternaria leaf blight epidemics in both experiments. The efficacy of chemical control in the 1997 experiment was higher than that observed in the 1996 experiment, probably because of the more frequent application of sprays in 1997. Nevertheless, despite the intensive application of fungicides, disease severity in the highly susceptible cv. Presto reached a level of 80 to $95 \%$ by the end of the season. By contrast, in plots of the most resistant cvs. Senior and Bolero, disease severity was 10 to $42 \%$ by the end of the season (Fig. 1C and D). For each cultivar, values of $r$ in sprayed and unsprayed plots did not differ significantly (Table 1). Thus, the effect of fungicides was to postpone the entire epidemic rather

TABLE 1. Effects of host resistance and chemical control on the suppression of Alternaria leaf blight (caused by Alternaria dauci) of carrot in two field experiments $^{\mathrm{x}}$

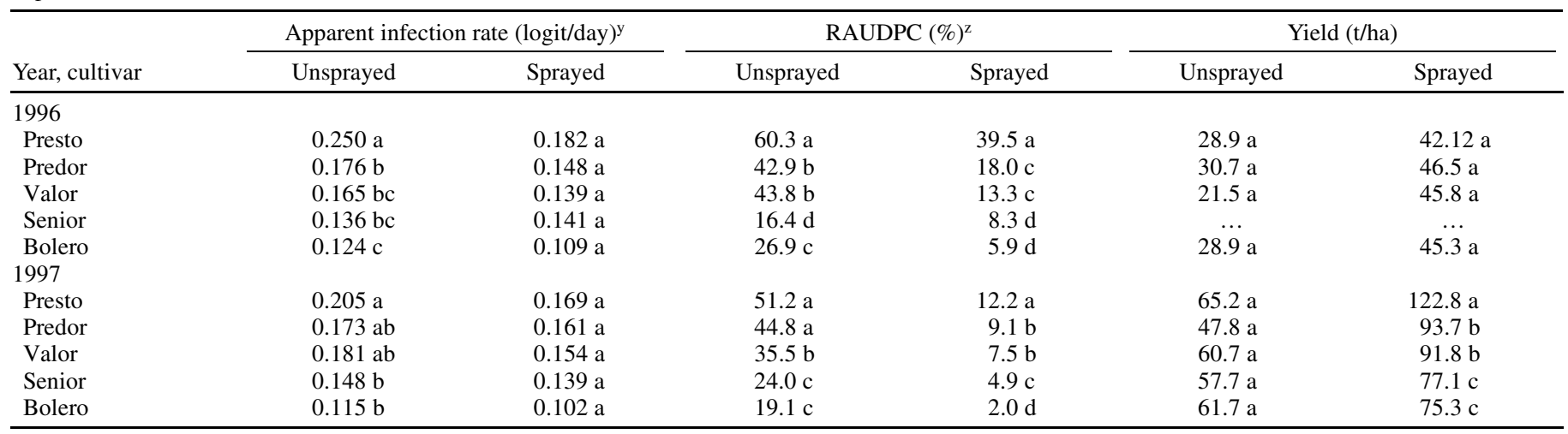

${ }^{\mathrm{x}}$ Numbers in each column, in each experiment, followed by the same letters are not significantly different as determined by Fisher's protected least significant difference test at $P \leq 0.05 ; \ldots=$ data not available. Differences in the apparent infection rate between sprayed and unsprayed cultivars were not significant at $P \leq 0.05$ as determined (for each cultivar) by means of a $t$ test. Differences in RAUDPC and yield between sprayed and unsprayed cultivars were significant at $P \leq 0.05$ as determined (for each cultivar) by means of a $t$ test.

y The apparent infection rate was calculated from logit-transformed disease percentage ratings presented in Figure 1.

${ }^{\mathrm{z}} \mathrm{RAUDPC}=$ relative area under the disease progress curve.

TABLE 2. Joint action of host resistance and chemical control on suppression of Alternaria leaf blight (caused by Alternaria dauci) of carrot in two field experiments in 1996 and 1997

\begin{tabular}{|c|c|c|c|c|c|c|c|}
\hline \multicolumn{2}{|c|}{ Treatment } & \multicolumn{2}{|c|}{ Observed control efficacy $(\%)^{\mathrm{w}}$} & \multicolumn{2}{|c|}{ Predicted control efficacy $(\%)^{\mathrm{x}}$} & \multicolumn{2}{|c|}{ Synergy factor ${ }^{y}$} \\
\hline Cultivar $^{\mathrm{Z}}$ & Chemical control & 1996 & 1997 & 1996 & 1997 & 1996 & 1997 \\
\hline Presto & Sprayed & 34.5 & 76.1 & $\ldots$ & $\cdots$ & $\ldots$ & $\ldots$ \\
\hline Senior & Unsprayed & 72.8 & 53.1 & & & & $\cdots$ \\
\hline Bolero & Unsprayed & 55.4 & 62.7 & 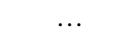 & & $\ldots$ & $\ldots$ \\
\hline Bolero & Sprayed & 90.2 & 96.1 & 70.7 & 91.0 & $1.27 *$ & 1.06 \\
\hline
\end{tabular}

${ }^{\text {w }}$ Observed control efficacy values were calculated by comparing the relative areas under the disease progress curve values in sprayed plots with those observed in unsprayed plots of cv. Presto.

x Predicted control efficacies and synergy factor values were calculated by using the Abbott formula $(20,21)$.

${ }^{\mathrm{y}}$ The null hypothesis that the synergy factor does not differ significantly from 1 was tested by means of a one-tailed $t$ test. An asterisk indicates that the null hypothesis was rejected at $P=0.05$.

${ }^{\mathrm{z}} \mathrm{Cv}$. Presto is highly susceptible to $\mathrm{A}$. dauci and cvs. Senior and Bolero are moderately resistant to the pathogen. 
than to decrease its intensification rate. The contribution of chemical control alone to disease suppression was estimated separately for each cultivar by comparing RAUDPC values for sprayed and unsprayed plots. For Predor, the contribution of chemical control was 58\% (in 1996) and 80\% (in 1997) and, for Senior and Bolero, it ranged from 49.3 to $89.5 \%$ (Table 2).

Epidemics of Alternaria leaf blight significantly reduced yields of all cultivars in both experiments. Application of ANOVA to the data revealed a nonsignificant interaction between chemical control and host resistance in the 1996 experiment $(P=0.34)$ but the interaction term was significant $(P=0.02)$ for the 1997 experiment (data not shown). In the 1996 experiment, the yields in sprayed plots were significantly higher than those in unsprayed plots for every cultivar. However, within each chemical control treatment, differences in yields between the various cultivars were nonsignificant (Table 1). In the 1997 experiment, yields in the sprayed plots were significantly higher than those in unsprayed plots, and the differences ranged from $13.6 \mathrm{t} / \mathrm{ha}$ (cv. Bolero) to $57.6 \mathrm{t} / \mathrm{ha}$ (cv. Presto). Differences in yield between unsprayed plots of the various cultivars were nonsignificant, but those in fungicide-treated plots were significant (Table 1).

The joint action of chemical control and host resistance was quantified by comparing epidemics in sprayed plots of the most resistant cultivars (Senior and Bolero) with those in unsprayed plots of the most susceptible cultivar (Presto). For all combinations of these two control measures, their integration improved control efficacy compared with application of either one of them alone. The integration enabled acceptable levels of disease suppression ( 86.2 to $96.1 \%$ ) to be achieved in all cultivars in both experiments (Table 2). In three out of the four comparisons, the

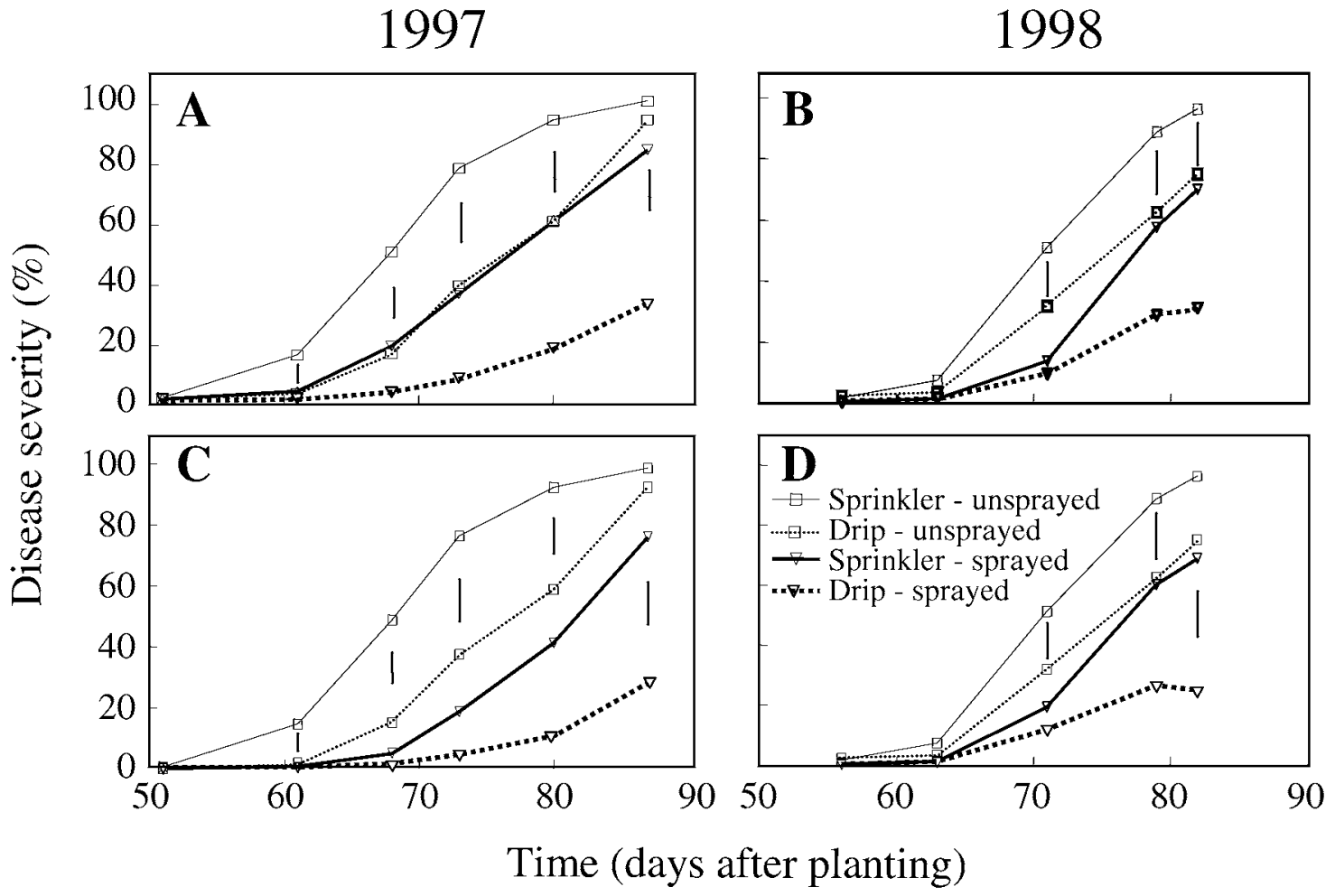

Fig. 2. Joint effect of the type of irrigation system and chemical control in the suppression of Alternaria leaf blight (caused by Alternaria dauci) of carrots in 2 years. A and B, plots treated with mancozeb $(2.0 \mathrm{~kg}$ a.i./ha); C and D, plots treated with tebuconazole $(0.19 \mathrm{~kg}$ a.i./ha). Severity values were back-transformed from Horsfall-Barratt scale assessments of whole plots. Vertical lines indicate the least significant difference $(P=0.05)$ for each disease assessment date.

TABLE 3. Effects of the type of irrigation system and chemical control on suppression of Alternaria leaf blight (caused by Alternaria dauci) of carrot in the 1997 experiment

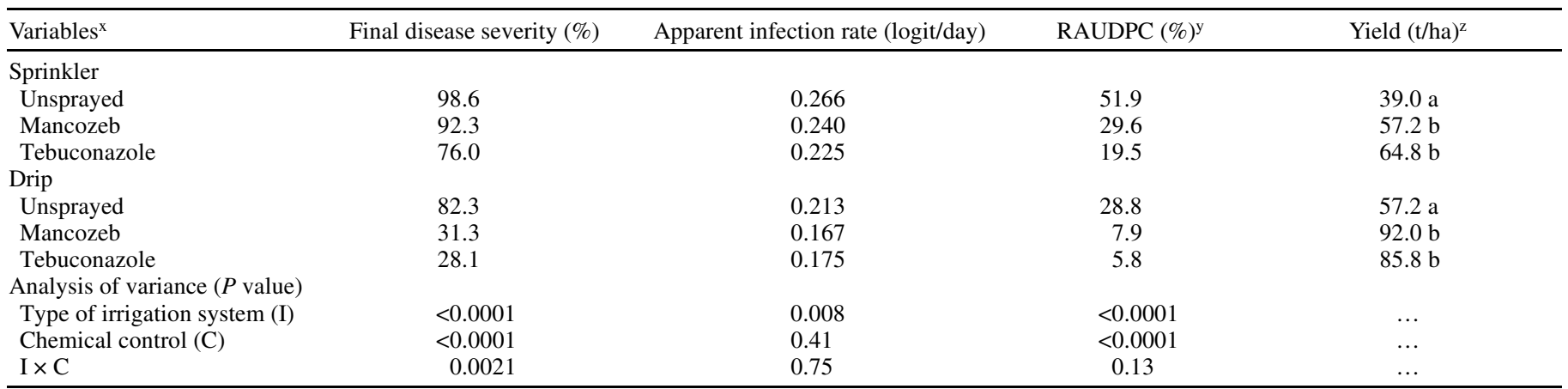

$\mathrm{x}$ Variables were type of irrigation system (sprinkler or drip) and chemical control treatments listed.

${ }^{\mathrm{y}} \mathrm{RAUDPC}=$ relative area under the disease progress curve.

${ }^{\mathrm{z}}$ Yields in the sprinkler- and drip-irrigated plots were harvested on different dates, so it was not possible to estimate the effect of the type of the irrigation system on yield. Within each irrigation system, numbers followed by the same letters are not significantly different, as determined by Fisher's protected least significant difference test at $P=0.05$. 
calculated synergy factor was not significantly different from 1 , indicating additive effects of the two control measures (Table 2).

Joint action of chemical control and drip irrigation. The first disease symptoms were observed in both experiments $\approx 50$ days after planting in sprinkler-irrigated, unsprayed plots. The disease progressed rapidly thereafter ( $r=0.27$ to 0.29$)$ and, within 3 weeks, disease severity had reached levels of 80 to $90 \%$. In drip-irrigated, unsprayed plots, the first disease symptoms were observed $\approx 10$ days later, and the rate of disease progression $(r=0.21)$ was significantly lower (Fig. 2; Tables 3 and 4). Application of fungicides significantly reduced disease severity and RAUDPC (for each irrigation treatment), but it did not affect $r$. For any specific chemical control treatment, disease severity, $r$, and RAUDPC were significantly lower in the drip- than in the sprinkler-irrigated plots. In general, the effects of the treatments on yields resembled their effects on disease suppression: yields in sprayed plots were significantly higher than those in unsprayed plots, and yields in drip-irrigated plots were higher than those in sprinkler-irrigated ones (the latter comparison was made only in the 1998 experiment) (Tables 3 and 4).

Relative to sprinkler irrigation, drip irrigation reduced disease intensity (expressed in RAUDPC) in unsprayed plots by 44.5 and $32.4 \%$ in 1997 and 1998, respectively (Tables 3 and 4). These values may be considered as the contribution of drip irrigation alone to disease suppression. However, sprinkler versus drip irrigation also may affect disease development via chemical control efficacy. The magnitude of that effect was estimated by comparing chemical control efficacy in drip- and sprinkler-irrigated plots. The improvements in control efficacy of the fungicides in dripirrigated plots were 9 and $28.6 \%$, respectively, in the two experiments. Differences in final disease severity, $r$, RAUDPC, and yield between plots treated with the protectant fungicide mancozeb and those treated with the systemic fungicide tebuconazole were small in both experiments (Tables 3 and 4).
Integration of chemical control and drip irrigation markedly improved control efficacy compared with the use of either one of these measures separately. The integration enabled an acceptable level of disease suppression (73 to $89 \%$ ) to be achieved in both experiments (Fig. 2; Tables 3 and 4). Yields in these plots were higher by 21 to 53 t/ha (in 1997) and 4.9 to 18.5 t/ha (in 1998). When the joint action of chemical control and drip irrigation in $A$. dauci suppression was calculated, the synergy factor was significantly greater than 1 in three out of the four comparisons, indicating synergistic effects of the two control measures (Table 5).

Joint action of control measures: a literature review. A literature review was performed to determine the possible interactions between control measures, and 19 studies were reviewed. They addressed the integration of chemical with genetic, biological, or cultural measures; and cultural with genetic or biological measures (Table 6). In each of these studies, control measures had been implemented, both alone and integrated with one another (with the same dosages and spraying intervals). We used the published data to calculate the efficacy levels of the joint action and to estimate the value of the synergy factor according to the Abbott formula $(20,21)$. Some of the reports included more than one experiment (or treatments within experiments); therefore, average values of the synergy factor for each report were calculated. Out of the 19 reviewed cases, in $14(73.6 \%)$ the calculated synergy factors ranged from 0.93 to 1.09 , suggesting additive effects. In the other five cases (26.4\%), the synergy factors were greater than 1.3 , implying that the joint action of these control measures was synergistic (Table 6).

\section{DISCUSSION}

The various control measures used in this study had differing effects on the time course of the development of Alternaria leaf blight. Whereas host resistance and drip irrigation affected both

TABLE 4. Effects of the type of irrigation system and chemical control on suppression of Alternaria leaf blight (caused by Alternaria dauci) of carrots in the 1998 experiment

\begin{tabular}{|c|c|c|c|c|}
\hline Variables $^{y}$ & Final disease severity $(\%)$ & Apparent infection rate (logit/day) & RAUDPC $(\%)^{\mathrm{z}}$ & Yield (t/ha) \\
\hline \multicolumn{5}{|l|}{ Sprinkler } \\
\hline Mancozeb & 70.0 & 0.229 & 20.9 & 49.1 \\
\hline \multicolumn{5}{|l|}{ Drip } \\
\hline Unsprayed & 75.0 & 0.211 & 28.7 & 45.1 \\
\hline Mancozeb & 31.3 & 0.178 & 11.4 & 59.2 \\
\hline Tebuconazole & 25.0 & 0.188 & 10.9 & 57.1 \\
\hline Chemical control (C) & $<0.0001$ & 0.60 & $<0.0001$ & 0.007 \\
\hline $\mathrm{I} \times \mathrm{C}$ & 0.29 & 0.95 & 0.50 & 0.670 \\
\hline
\end{tabular}

y Variables were type of irrigation system (sprinkler or drip) and chemical control treatments listed.

${ }^{\mathrm{z}}$ RAUDPC $=$ relative area under the disease progress curve.

TABLE 5. Joint action of the type of irrigation system and chemical control on suppression of Alternaria leaf blight (caused by Alternaria dauci) of carrots in two field experiments in 1997 and 1998

\begin{tabular}{|c|c|c|c|c|c|c|c|}
\hline \multicolumn{2}{|c|}{ Treatment } & \multicolumn{2}{|c|}{ Observed control efficacy $(\%)^{x}$} & \multicolumn{2}{|c|}{ Predicted control efficacy $(\%)^{\mathrm{y}}$} & \multicolumn{2}{|c|}{ Synergy factor ${ }^{\mathrm{z}}$} \\
\hline Irrigation system & Chemical control & 1997 & 1998 & 1997 & 1998 & 1997 & 1998 \\
\hline Sprinkler & Mancozeb & 42.6 & 49.9 & $\ldots$ & $\ldots$ & $\ldots$ & $\ldots$ \\
\hline Drip & Unsprayed & 44.4 & 31.7 & & & & . \\
\hline Sprinkler & Tebuconazole & 62.3 & 44.7 & $\ldots$ & $\ldots$ & $\ldots$ & $\ldots$ \\
\hline Drip & Unsprayed & 44.4 & 31.7 & . & $\ldots$ & $\ldots$ & $\ldots$ \\
\hline Drip & Tebuconazole & 89.1 & 73.4 & 77.5 & 61.8 & $1.16^{*}$ & $1.20^{*}$ \\
\hline
\end{tabular}

${ }^{x}$ Observed control efficacy values were calculated by comparing the relative areas under the disease progress curve in sprayed plots with those observed in unsprayed plots irrigated with sprinkler irrigation.

y Predicted control efficacies and synergy factor values were calculated by using the Abbott formula $(20,21)$.

${ }^{z}$ The null hypothesis that the synergy factor does not differ significantly from 1 was tested by means of a one-tailed $t$-test. An asterisk indicates that the null hypothesis was rejected at $P=0.05$. 
the time of disease onset (it postponed the entire development of the epidemic) and the rate of disease progression, chemical control affected only the latter. In all cases, use of any one of the tested measures alone did not result in an acceptable level of disease suppression. The final severity of Alternaria leaf blight in plots of the susceptible cv. Presto sprayed with fungicides (i.e., those protected solely by chemical control), in unsprayed plots of the moderately resistant cvs. Senior or Bolero (i.e., those protected solely by host resistance), or in unsprayed plots irrigated via a drip system (i.e., those protected solely by the cultural measure used), ranged from 60 to $95 \%$. Control efficacy values for these treatments were $60 \pm 22,58 \pm 11$, and $39 \pm 20 \%$ (values are means for two to four experiments \pm standard error). On the other hand, the joint action of two control measures improved control efficacy compared with that observed for the separate measures. The final severity of Alternaria leaf blight in fungicidetreated plots of the moderately resistant cvs. Senior and Bolero (i.e., those protected by both chemical control and host resistance) and in fungicide-treated plots irrigated via a drip system (i.e., those protected by both chemical control and the cultural measure used) ranged from 10 to $38 \%$. Control efficacy values for these treatments were $91 \pm 8$, and $82 \pm 23 \%$, respectively. Moreover, yields in plots protected by two control measures simultaneously were higher by 10.1 to 28.6 t/ha than those in the plots protected by either of the measures alone. These data demonstrate the advantages of implementing more than one control measure simultaneously in the management of the disease.

Alternaria leaf blight in drip-irrigated plots was significantly less severe than in sprinkler-irrigated plots. This may be because the drip system does not wet the foliage; therefore, microclimatic conditions conducive to the pathogen were not intensified. Similar results have been reported for downy mildews in melon (caused by Pseudoperonospora cubensis) (24) and lettuce (caused by Bremia lactucae) (38), and for rust (caused by Uromyces spp.) in Vigna unguiculata (37). Furthermore, the chemical control efficacy was higher in drip-irrigated plots than in sprinkler-irrigated plots. This too, may be attributed to the difference in the microclimatic condi- tions; however, in addition, drip irrigation does not wash fungicide deposits from the foliage, as happens in sprinkler-irrigated crops $(23,24)$. The choice of the irrigation system that prevented foliage wetting was estimated to have contributed $38.4 \%$ (mean of the two experiments) to Alternaria leaf blight suppression. The contribution to be attributed to the prevention of fungicide wash-off was $18.2 \%$ on the average, approximately half of that attributed to the avoidance of a pathogen-conducive microclimate.

Because systemic fungicides penetrate into the plant tissues, they are considered to be less liable to be washed off than protectant fungicides. Consequently, it was expected that the differences in control efficacy between the systemic fungicide tebuconazole and the protectant fungicide mancozeb would be greater in the sprinkler-irrigated plots than in the drip-irrigated plots. However, the two fungicides exhibited comparable efficacy in both irrigation treatments. Recently, it was reported that the efficacy of fungicides used for suppression of $A$. dauci in sprinkler-irrigated plots was not necessarily related to the systemic characteristics of the compounds: chlorothalonil (a protectant fungicide) was found significantly more effective than the systemic fungicides tebuconazole and flutrifol (1).

In general, the joint action of control measures may be antagonistic, additive, or synergistic. In the present study, it was found that, for the carrot $-A$. dauci system, integration of chemical control and host resistance resulted in additive effects and that of chemical control and drip irrigation was synergistic in most cases. A literature review was performed to determine whether these findings generally are applicable to chemical, genetic, and cultural control measures, or if they apply only to the particular cases studied. Regardless of which control measures were integrated, the most common effects of joint action were additive. In fact, it seems that additive effects are the rule and synergistic or antagonistic effects are the exception. Additive affects are to be expected when each of the control measures affects the pathogen independently and they do not affect each other. Antagonistic effects of two control measures were not observed in the present study or reported in the literature we reviewed, but this type of interaction

TABLE 6. The joint action of disease control measures as determined from data retrieved in a literature review

\begin{tabular}{|c|c|c|c|c|c|c|}
\hline Integrated control measures & Host & Pathogen & Disease variable $^{w}$ & $\begin{array}{c}\text { No. of } \\
\text { comparisons }\end{array}$ & $\mathrm{SF}^{\mathrm{x}}$ & Reference \\
\hline \multicolumn{7}{|l|}{ Chemical and genetic } \\
\hline Fungicides and host resistance & Chickpea & Didymella rabiei & RAUDPC & 6 & 1.03 & 33 \\
\hline Fungicides and host resistance & Potato & Phytophthora infestans & AUDPC & 4 & 1.15 & 12 \\
\hline Fungicides and host resistance & Potato & P. infestans & RAUDPC & 2 & 1.00 & 15 \\
\hline Fungicides and host resistance & Potato & Alternaria solani & AUDPC & 1 & 1.04 & 30 \\
\hline Fungicides and host resistance & Potato & A. solani and $P$. infestans & RAUDPC & 4 & 1.00 & 32 \\
\hline Methyl bromide and host graftingy & Melon & Monosporascus cannonballus & Wilt incidence & 1 & 1.01 & 3 \\
\hline \multicolumn{7}{|l|}{ Chemical and biological } \\
\hline PCNB and Trichoderma harzianum ${ }^{\mathrm{z}}$ & Iris bulbs & Rhizoctonia solani & Disease incidence & 2 & 0.98 & 2 \\
\hline Fungicides and T. harzianum T39 & Cucumber & Botrytis cinerea & Fruit infection & 5 & 0.99 & 8 \\
\hline \multicolumn{7}{|l|}{ Chemical and cultural } \\
\hline Methyl bromide and solarization & Tomato & $\begin{array}{l}\text { Fusarium oxysporum f. sp. } \\
\text { radicis-lycopersici }\end{array}$ & Wilt incidence & 1 & 1.30 & 34 \\
\hline \multicolumn{7}{|l|}{ Cultural and genetic } \\
\hline Solarization and host resistance & Potato & Verticillium dahliae & Wilt incidence & 5 & 1.09 & 4 \\
\hline \multicolumn{7}{|l|}{ Cultural and biological } \\
\hline Solarization and T. harzianum & Iris bulbs & R. solani & Disease incidence & 1 & 0.99 & 2 \\
\hline Solarization and $T$. harzianum & Potato & R. solani & Diseased plants & 2 & 0.93 & 7 \\
\hline Solarization and T. harzianum & Potato & V. dahliae & Wilt incidence & 3 & 0.97 & 7 \\
\hline Solarization and T. harzianum & Tomato & $\begin{array}{l}\text { F. oxysporum f. sp. } \\
\text { radicis-lycopersici }\end{array}$ & Wilt incidence & 1 & 1.70 & 34 \\
\hline Solarization and T. harzianum & Potato & Sclerotium rolfsii & Diseased plants & 1 & 2.03 & 7 \\
\hline Solarization and Gliocladium virens & Tomato & S. rolfsii & Disease incidence & 2 & 1.85 & 27 \\
\hline Climate control and Aureobasidium pullulans & Cucumber & B. cinerea & Fruit infection & 2 & 1.02 & 6 \\
\hline Climate control and Cryptococcus albidus & Cucumber & B. cinerea & Fruit infection & 2 & 1.00 & 6 \\
\hline Climate control and T. harzianum T39 & Cucumber & B. cinerea & Fruit infection & 2 & 1.03 & 6 \\
\hline
\end{tabular}

${ }^{\mathrm{w}} \mathrm{AUDPC}=$ area under the disease progress curve and RAUDPC $=$ relative AUDPC.

x $\mathrm{SF}=$ synergy factor as calculated by using the Abbott formula $(21,21)$.

y Host grafting using resistant Cucurbita rootstock.

z $\mathrm{PCNB}=$ pentachloronitrobenzene. 
would be likely if one control measure nullified the efficacy of the other, directly or indirectly. For example, antagonistic effects could be expected if a biocontrol agent were integrated with a chemical compound that restricted its efficacy, or if a chemical compound were applied in a greenhouse in which the climate was controlled in a way that predisposes the host to increased susceptibility to the pathogen. Synergistic effects of control measures are to be expected when one control measure directly improves the efficacy of the other, or when one control measure induces host resistance or predisposes the pathogen to increased susceptibility. An example of the former possibility was observed in the present study, when fungicides were applied in drip-irrigated plots; examples of the latter possibility were found in our literature review $(7,27,34)$. Synergistic effects were apparent when a cultural measure (soil solarization) was integrated with chemical (methyl bromide) or biological (T. harzianum or Gliocladium virens) measures for the suppression of Sclerotium rolfsii or Fusarium oxysporum f. sp. radicis-lycopersici. Synergism was attributed to weakening effects of solarization on the resting structures (sclerotia and chlamydospores) of the pathogens (19). The sublethal heating created by solarization was insufficient to reduce the viability of the resting structures effectively, but it was sufficient to increase the vulnerability of the resting structures to methyl bromide or the biocontrol agents (19). Furthermore, it recently was demonstrated that a sequence of heating or solarization followed by fumigation is more effective than the reverse sequence (9). When solarization was integrated with host resistance or with T. harzianum for the suppression of Rhizoctonia solani or Verticillium dahliae, the joint action was additive rather than synergistic. These results may be attributed to the fact that the resting structures of $R$. solani or $V$. dahliae are more vulnerable to heat than those of $S$. rolfsii or $F$. oxysporum f. sp. radicis-lycopersici (J. Katan, personal communication) and the sublethal heating that occurs during solarization is sufficient to reduce their viability directly. Consequently, the indirect effects of heating, which would result in synergism, are precluded.

The results presented in this study constitute evidence of the advantages of the concurrent use of more than one control measure in the suppression of $A$. dauci, a pathogen against which implementation of single measures did not provide adequate levels of disease reduction. Moreover, the present findings reveal commonalities among the various combinations of control measures and enable generalities to be formulated regarding the joint action of these measures. This may facilitate the more effective selection of candidate measures to be used in the development of IPM strategies in the future.

\section{ACKNOWLEDGMENTS}

This research was supported in part by the Israel Vegetable Growers' Board and by the Chief Scientist of the Israeli Ministry of Agriculture. Contribution 528/02 from the Agricultural Research Organization. We thank A. Yaniv for technical assistance in the field experiments.

\section{LITERATURE CITED}

1. Ben-Noon, E., Shtienberg, D., Shlevin, E., Vintal, H., and Dinoor, A. 2001. Optimization of chemical suppression of Alternaria dauci, the causal agent of Alternaria leaf blight in carrots. Plant Dis. 85:1149-1156.

2. Chet, I., Elad, Y., Kalfon, A., Hadar, Y., and Ketan, J. 1982. Integrated control of soilborne and bulbborne pathogens in iris. Phytoparasitica 10:229-236.

3. Cohen, R., Pivonia, S., Burger, Y., Edelstein, M., Gamliel, A., and Katan, J. 2000. Towards integrated management of monosporascus wilt of melons in Israel. Plant Dis. 84:496-505

4. Davis, J. R., and Sorensen, L. H. 1986. Influence of soil solarization at moderate temperatures on potato genotypes with differing resistance to Verticillium dahliae. Phytopathology 76:1021-1026.

5. De Waard, M. A. 1996. Synergism and antagonism in fungicide mixtures containing sterol demethylation inhibitors. Phytopathology 86:12801283.
6. Dik, A. J., and Elad, Y. 1999. Comparison of antagonists of Botrytis cinerea in greenhouse-grown cucumber and tomato under different climatic conditions. Eur. J. Plant Pathol. 105:123-137.

7. Elad, Y., Katan, J., and Chet, I. 1980. Physical, biological, and chemical control integrated for soilborne diseases in potatoes. Phytopathology 70:418-422.

8. Elad, Y., Zimand, G., Zaqs, Y., Zuriel, S., and Chet, I. 1993. Use of Trichoderma harzianum in combination or alternation with fungicides to control cucumber grey mould (Botrytis cinerea) under commercial greenhouse conditions. Plant Pathol. 42:324-332.

9. Eshel, D., Gamliel, A., Grinstein, A., Di Primo, P., and Katan, J. 2000. Combined soil treatment and sequence of application in improving the control of soilborne pathogens. Phytopathology 90:751-757.

10. Fry, W. E. 1977. Integrated control of potato late blight-effects of polygenic resistance and techniques of timing fungicide applications. Phytopathology 67:4156-420.

11. Fry, W. E. 1978. Quantification of general resistance of potato cultivars and fungicide effects for integrated control of potato late blight. Phytopathology 68:1650-1655.

12. Fry, W. E., Apple, A. E., and Bruhn, J. A. 1983. Evaluation of potato late blight forecasts modified to incorporate host resistance and fungicide weathering. Phytopathology 73:1054-1059.

13. Gisi, U. 1996. Synergistic interaction of fungicides in mixtures. Phytopathology 86:1273-1279.

14. Goodell, P. B., and Nunez, J. 1997. Carrot variety evaluation for resistance to foliar and root pathogens and root nematodes. Annu. Rep. Calif. Fresh Carrot Advis. Board 77-84.

15. Grünwald, N. K., Rubio-Covarrubias, O. A., and Fry, W. E. 2000. Potato late-blight management in Toluca Valley: Forecasts and resistant cultivars. Plant Dis. 84:410-416.

16. Guetsky, R., Shtienberg, D., Elad, Y., and Dinoor, A. 2001. Combining biocontrol agents to reduce variability of biological control. Phytopathology 91:621-627.

17. Holly, J. D., Hall, R., and Hofstra, G. 1985. Effects of cultivar resistance, leaf wetness and temperature on rate of development of potato early blight. Can. J. Plant Sci. 65:179-184.

18. Horsfall, J. G., and Barratt, R. W. 1945. An improved grading system for measuring plant disease. (Abstr.) Phytopathology 35:655.

19. Katan, J. 1996. Soil solarization: Integrated control aspects. Pages 250-278 in: Principles and Practices of Managing Soilborne Plant Pathogens. R. Hall, ed. The American Phytopathological Society, St. Paul, MN.

20. Kosman, E., and Cohen, Y. 1996. Procedures for calculating the differentiating synergism and antagonism in action of fungicide mixtures. Phytopathology 86:1263-1272.

21. Levy, Y., Benderly, M., Cohen, Y., Gisi, U., and Bassand, D. 1986. The joint action of fungicides in mixtures; Comparison of two methods for synergy calculation. EPPO Bull. 16:651-657.

22. Netzer, D., and Kenneth, R. G. 1969. Persistence and transmission of Alternaria dauci (Kühn) Groves \& Skolko in the semi-arid conditions of Israel. Ann. Appl. Biol. 63:289-294.

23. Palti, J. 1981. Cultural Practices and Infectious Crop Diseases. SpringerVerlag, Berlin.

24. Palti, J., and Shoham, H. 1983. Trickle irrigation and crop disease management. Plant Dis. 67:703-705.

25. Pelletier, J. R., and Fry, W. E. 1989. Characterization of resistance to early blight in three potato cultivars: Incubation period, lesion expansion rate and spore production. Phytopathology 79:1352-1359.

26. Pelletier, J. R., and Fry, W. E. 1990. Characterization of resistance to early blight in three potato cultivars: Receptivity. Phytopathology 80:361-366.

27. Ristaino, J. B., Perry, K. B., and Lumsden, R. D. 1991. Effect of solarization and Gliocladium virens on sclerotia of Sclerotium rolfsii, soil microbiota, and the incidence of southern blight of tomato. Phytopathology 81:1117-1124.

28. Rotem, J. 1994. The Genus Alternaria. Biology, Epidemiology and Pathogenicity. The American Phytopathological Society, St. Paul, MN.

29. Samoucha, Y., and Cohen, Y. 1986. Efficacy of systemic and contact fungicide mixtures in controlling late blight in potatoes. Phytopathology 76:855-859.

30. Shtienberg, D., Blatchinsky, D., Kremer, Y., Ben-Hador, G., and Dinoor, A. 1995. Integration of genotype and age-related resistance to reduce fungicide use in the management of Alternaria diseases of cotton and potatoes. Phytopathology 85:995-1002.

31. Shtienberg, D., and Elad, Y. 1997. Incorporation of weather forecasting to integrated, chemical-biological management of Botrytis cinerea. Phytopathology 87:332-340.

32. Shtienberg, D., Raposo, R., Bergeron, S. N., Legard, D. E., Dyer, A. T., and Fry, W. E. 1994. Incorporation of cultivar resistance in a reduced- 
sprays strategy to suppress early and late blight on potato. Plant Dis. 78:23-26.

33. Shtienberg, D., Vintal, H., Brener, S., and Retig, B. 2000. Rational management of Didymella rabiei in chickpea by integration of genotype resistance and curative application of fungicides. Phytopathology 90:834-842.

34. Sivan, A., and Chet, I. 1993. Integrated control of Fusarium crown and root rot of tomato with Trichoderma harzianum in combination with methyl bromide or soil solarization. Crop Prot. 12:380-386.

35. Strandberg, J. O. 1992. Alternaria species that attack vegetable crops: Biology and options for disease management. Pages 175-208 in: Alter- naria: Biology, Plant Diseases and Metabolites. J. Chelkowski and A. Visconti, eds. Elsevier Scientific Publications, Amsterdam, the Netherlands. 36. Strandberg, J. O. 1993. Alternaria leaf blight. Bad news for carrot production everywhere. Carrot Count. 1:24-25.

37. Wessolek, G., and Meier, U. 1985. Influence of different irrigation methods and intervals on the infection of Vigna unguiculata ssp. cylindrica by Uromyces spp. under arid conditions. Z. Pflanzenkrankh. Pflanzenschutz 92:594-599.

38. Wu, B. M., Subbarao, K. V., van Bruggen, A. H. C., and Koike, S. T. 2001. Comparison of three fungicide spray advisories for lettuce downy mildew. Plant Dis. 85:895-900. 